\title{
The laser-welded joint of an austenitic corrosion-resistant steel and a titanium alloy with an intermediate copper insert
}

\author{
I. A. Veretennikova ${ }^{1, \dagger}$, N. B. Pugacheva ${ }^{2}$, E. O. Smirnova ${ }^{1}$, N. S. Michurov ${ }^{1}$ \\ †irincha@imach.uran.ru \\ ${ }^{1}$ Institute of Engineering Science of Ural Branch of RAS, 34 Komsomol'skaya st., Yekaterinburg, 620049, Russia \\ ${ }^{2}$ UISFS of EMERCOM of Russia, 22 Mira st., Yekaterinburg, 620062, Russia
}

\begin{abstract}
The microstructure and local mechanical properties of zones of $12 \mathrm{Cr} 18 \mathrm{Ni10Ti}$ steel and a titanium alloy VT1-0 with an intermediate copper insert joint were carried out. The study was performed using electronic scanning microscopy, microindentation and scratch tests. The phase composition was determined by the EBSD analysis. Dissolution and mixing of welded materials in a copper are observed. The material of joint is a supersaturated solid solution of $\mathrm{Fe}, \mathrm{Ni}, \mathrm{Cr}$, Ti in the copper crystal lattice with uniformly distributed particles of $\mathrm{TiFe}, \mathrm{Ti}(\mathrm{Fe}, \mathrm{Cr})_{2}$, and $\mathrm{CuTi}_{2}$. A diffusion zones with a changed chemical composition $10 \div 150 \mu \mathrm{m}$ thick and a microhardness of $2,9 \div 3,4 \mathrm{GPa}$ are formed on the boundary with steel, and at a boundary with a titanium alloy $-50 \div 100 \mu \mathrm{m}$ thick and the microhardness of $4,6 \div 6 \mathrm{GPa}$. The microhardness of steel is $2,7 \div 3,1 \mathrm{GPa}$, titanium alloy $-2,4 \div 2,8 \mathrm{GPa}$, solid solution based on copper $-1,7 \div 2,1 \mathrm{GPa}$, intermetallides $-3,8 \div 4,9 \mathrm{GPa}$. The stress-strain diagrams for zones of the joint are received using the original technique for determining coefficients of the "stress-strain" diagram by microindentation and scratch tests. The diffusion zone on the boundary with titanium is greater strength. There is established the formation of a solid solution based on $\beta$-titanium and dispersed particles of $\mathrm{CuTi}_{2}$ and then - intermetallides of $\mathrm{Ti}(\mathrm{Fe}, \mathrm{Cr})_{2}$. The obtained data can be used to estimate stress-strain state, strength and efficiency of the joint under load and to give recommendations for practical.
\end{abstract}

Keywords: laser welding, intermediate insert, microstructure, micromechanical properties, supersaturated solid solutions.

УДК: 539.374 .1

\section{Лазерное сварное соединение титанового сплава ВТ1-0 и стали 12X18Н10T с промежуточной медной вставкой}

\author{
Веретенникова И. А. ${ }^{1, \dagger}$, Пугачева Н. Б. ${ }^{2}$, Смирнова Е. О. ${ }^{1}$, Мичуров Н. С. ${ }^{1}$ \\ ${ }^{1}$ ФГБУН Институт машиноведения УрО РАН, ул. Комсомольская, 34, Екатеринбург, 620049, Россия \\ 2УрИ ГПС МЧС РФ, ул. Мира, 22, Екатеринбург, 620062, Россия
}

В работе проведено исследование микроструктуры и локальных механических свойств отдельных зон соединения титанового сплава ВТ1-0 и нержавеющей стали 12Х18Н10Т с промежуточной вставкой из меди, полученного с помощью $\mathrm{CO}_{2}$-лазера. Исследования выполнены с использованием электронной сканирующей микроскопии, кинетического микроиндентирования пирамидкой Берковича и скратч-тестов. Методом EBSD-анализа установлен фазовый состав всех зон сварного соединения. При формировании соединения «титановый сплав ВТ1-0 - медная вставка - сталь 12Х18Н10Т» наблюдается растворение и перемешивание свариваемых материалов в медной прослойке. Материал сварного шва представляет собой пересыщенный твердый раствор $\mathrm{Fe}, \mathrm{Ni}, \mathrm{Cr}$, Ti в кристаллической решетке меди с равномерно распределенными частицами интерметаллидов $\mathrm{TiFe}, \mathrm{Ti}(\mathrm{Fe}, \mathrm{Cr})_{2}$ и $\mathrm{CuTi}_{2}$. На границе со сталью формируется диффузионная зона с измененным химическим составом толщиной $10 \div 150$ мкм и микротвердостью 2,9 $\div 3,4$ ГПа, а на границе с титановым сплавом - толщиной $50 \div 100$ мкм и микротвердостью 4,6 $\div 6$ ГПа. Микротвердость стали 12 Х 18 Н10Т находится в диапазоне $2,7 \div 3,1$ ГПа, титана ВТ1-0 - 2,4 $\div$, 8 ГПа, твердого раствора на основе меди $-1,7 \div 2,1$ ГПа, интерметаллидов - 3,8 4,9 ГПа. Для всех зон и структурных составляющих сварного соединения построены диаграммы упрочнения с применением оригинальной методики по обработке кривых нагружения, полученных в результате микроиндентирования и скратч-тестов. Большей прочностью характеризуется пограничный слой сварного шва с титаном, в котором установлено образование пересыщенного твердого раствора на основе $\beta$-титана и дисперсных частиц $\mathrm{CuTi}_{2}$, затем - интерметаллиды $\mathrm{Ti}(\mathrm{Fe}, \mathrm{Cr})_{2}$. Значения прочностных характеристик пограничного слоя со сталью находятся на уровне 12Х18Н10Т. Полученные экспериментальные данные могут быть использованы при решении задач, связанных с оценкой напряженно-деформированного состояния, прочности и работоспособности сварного шва под нагрузкой, позволят дать практически рекомендации для дальнейшей работы с данными видами швов.

Ключевые слова: лазерная сварка, промежуточная вставка, микроструктура, микромеханические свойства. 


\section{1. Введение}

Соединение разнородных материалов, например титана и нержавеющих сталей, представляет большой интерес для космического, авиационного и нефтехимического машиностроения. Применение подобных сварных конструкций обеспечивает снижение веса изделий, что в ряде случаев имеет решающее значение. В процессе сварки возникает ряд технологических трудностей, обусловленных, во-первых, существенными различиями теплофизических свойств соединяемых материалов, во-вторых, образованием в области шва большого числа интерметаллидов $\mathrm{TiFe}$ и $\mathrm{TiFe}_{2}$, склонных к хрупкому разрушению [1]. Специальным технологическим приемом, позволяющим исключить или существенно снизить охрупчивание зоны первичной кристаллизации, является использование барьерных слоев из других металлов и сплавов [2-4]. Металл вставки должен обладать хорошей свариваемостью как с титаном, так и со сталью, и при этом необходимо учитывать коррозионную стойкость соединения из разнородных металлов, включая вставку, если сварная конструкция предназначается для работы в агрессивных средах. Например, в качестве вставок использовались медь, бронза и др. [3], ниобий [1], медь [5 - 7]. Наиболее эффективный барьерный слой формируется при использовании медной вставки.

Современной тенденцией в изучении материалов является применение комплексного подхода к разработке и дальнейшей эксплуатации полученного изделия. Микроструктуру лазерных швов изучают традиционными методами материаловедения. Работ в этой области достаточно много [8-11]. Изучение микромеханических свойств отдельных зон лазерного сварного шва традиционными методами затруднительно, поскольку изготовить образцы необходимых размеров технически сложно (ширина сварного шва составляет не более 1.5 мм, зон термического влияния - от 0,6 до 1 мм). В некоторых случаях, в частности при проектировании изделий и конструкций, содержащих лазерное сварное соединение, необходимо оценивать напряженно-деформированное состояние всех зон соединения, имеющих разное строение и отличающиеся микромеханические свойства. Ранее в $[4,5]$ было показано, что при внешнем механическом нагружении в первую очередь разрушается материал зоны термического влияния на границе с титановым сплавом. В работах $[12,13]$ предложена и апробирована оригинальная методика, позволяющая получать диаграммы упрочнения in situ на основании экспериментальных данных по индентированию и царапанию индентором Берковича. Целью данной работы являлось комплексное исследование микроструктуры соединения титанового сплава ВТ1-0 и нержавеющей стали $12 \mathrm{X} 18 \mathrm{H} 10 \mathrm{~T}$ с промежуточной вставкой из меди, полученного с помощью $\mathrm{CO}_{2}$-лазера, выделение отдельных зон с построением диаграммы упрочнения для них.

\section{2. Материалы и методы исследования}

Исследовали сварные соединения листов толщиной 3 мм из титанового сплава ВТ1-0 и нержавеющей стали 12Х18Н10T, полученные с помощью $\mathrm{CO}_{2}$-лазера. Сварка выполнена в Институте теоретической и прикладной механики им. С. А. Христиановича СО РАН (г. Новосибирск) под руководством профессора, д.ф.-м.н. Оришича А.М. В качестве переходного материала, участвующего в формировании сварного шва, использовали пластину из меди марки M1 толщиной 1 мм. Для защиты шва от окисления применяли смесь газов $\mathrm{CO}_{2} /$ возд. = 1/7. При сварке использовали режим, характеризующийся мощностью лазерного излучения 2,2 кВт и скоростью перемещения лазерного луча 1 м/мин. Выбранный режим обеспечивает максимальные значения прочности получаемого сварного соединения [5 - 7].

Эксперименты проведены на оборудовании Центра коллективного пользования «Пластометрия» ИМАШ УрО РАН (г. Екатеринбург). Способ приготовления микрошлифов традиционный - механическое шлифование и механическое полирование на алмазных пастах различной дисперсности. Микроструктуру исследовали с применением метода анализа картин дифракции отраженных электронов (EBSD) на растровом электронном микроскопе TESCAN VEGA II XMU с приставкой Oxford NKLNordlysF+. Распределение химических элементов и локальный химический состав соединяемых материалов, сварного шва и прилегающих к ним диффузионных зон определяли при помощи энегродисперсионной приставки OXFORD INCA ENERGY 450 к растровому электронному микроскопу. Расчет молибденового эквивалента для околошовной зоны в титановом сплаве проводили по методике, описанной в [14]. Исследование распределения микротвердости материала осуществляли на наномеханическом комплексе NanoTriboindentor TI 950, с применением индентора в форме трехгранной пирамиды Берковича. Приведенный модуль упругости и микротвердость определяли по методике Оливера - Фарра [15]. Измерения производили на локальных участках, характеризующихся однородным химическим составом. Для определения диаграмм деформационного упрочнения материала зон сварного соединения была применена оригинальная методика $[12,13]$, основанная на результатах анализа испытаний по индентированию и царапанию материала совместно с результатами численного эксперимента на детальной конечно-элементной модели процесса испытания. Материал, в который осуществляется внедрение индентора упругопластический. Чисто упругая деформация имеет место только в начале процесса индентирования и подчиняется закону Гука. В пластическом состоянии материал подчиняется условию текучести Мизеса в виде степенной зависимости $\sigma_{s}=a \varepsilon^{b}$, где $\sigma_{s}-$ напряжение текучести Мизеca (сопротивление деформации); $\varepsilon$ - полная деформация по Мизесу; $a$ и $b$ - числовые эмпирические коэффициенты. Зная экспериментально полученные значения глубин вдавливания $h_{B}$ и царапания $h_{L}$, используя результаты многократного моделирования, определяли искомую пару значений коэффициентов $a$ и $b$ для исследуемого участка. 


\section{3. Результаты и обсуждение}

На Рис. 1а представлена структура поперечного сечения стыкового сварного шва, полученного после лазерной сварки титанового сплава ВТ1-0 и нержавеющей стали $12 \mathrm{X} 18 \mathrm{H} 10 \mathrm{~T}$ через промежуточную пластину из меди, по выбранному технологическому режиму. Ширина сварного шва составляет 1,3 мм. В материале шва наблюдается интенсивное диффузионное взаимодействие соединяемых материалов с промежуточной вставкой. На Рис. $1 \mathrm{~b}$ представлено распределение химических элементов $\mathrm{Ti}, \mathrm{Fe}, \mathrm{Cu}$ по сечению шва. Благодаря конвективному перемешиванию расплава в сварочной ванне под действием движущегося луча лазера [5] и частичному расплавлению титана и стали (расплавляется по 0,15 мм толщины листа каждого из соединяемых материалов) титан из сплава ВТ1-0, а железо, никель и хром из стали равномерно распределены по всей ширине шва. В результате диффузионного взаимодействия расплавленного металла сварочной ванны с сохранившимися в твердом состоянии соединяемыми материалами титан проникает в зону термического влияния на границе со сталью, а железо, никель и хром - в зону на границе с титановым сплавом.

На Рис. 2 приведены фотографии различных зон сварного шва. В центральной части шва (Рис. 2a) материал представляет собой композицию, состоящую из пересыщенного твердого раствора $\mathrm{Ti}, \mathrm{Fe}, \mathrm{Cr}, \mathrm{Ni}$ в ГЦК решетке $\mathrm{Cu}$ и округлых частиц интерметаллидов $\mathrm{Ti}(\mathrm{Fe}, \mathrm{Cr})_{2}$ и $\mathrm{TiCu}_{3}$, количество которых не поддается систематизации и размер начинает варьироваться от 0,3 мм в сторону уменьшения. На границе шва с титановым сплавом (Рис. 2b) и коррозионностойкой сталью (Рис. 2c) образуются диффузионные зоны, которые способствуют плавному перераспределению свойств между соединенными материалами. Переходная зона на границе с титановым сплавом представляет собой пересыщенный твердый раствор железа, никеля, хрома и меди в решетке титана, а на границе со сталью - пересыщенный твердый раствор титана, меди, никеля и хрома в решетке железа. Со стороны титанового сплава между основным металлом и наплавленным композиционным материалом явно просматривается промежуточный слой, толщина которого варьируется в диапазоне 50...100 мкм. Со стороны нержавеющей аустенитной стали толщина диффузионной зоны меняется от 10 мкм до 150 мкм, кроме того могут наблюдаться локальные области размером около 0,3 мм, отличающиеся по химическому составу от сварного шва и нержавеющей стали. Таким образом, зоны термического влияния при лазерной сварке разнородных материалов представляют собой диффузионные зоны с измененным химическим составом.

Изменение фазового состава сварного шва наглядно приведено на рисунке S1 (дополнительный материал). На границе сварного шва со сплавом ВТ1-0 со стороны титанового сплава обнаружена переходная зона, состоящая из твердого раствора химических элементов в $\beta$-титане с равномерно расположенными мелкодисперсными интерметаллидами (Рис. S2, дополнительный материал). Фиксация на границе со сварным швом $\beta$-структуры свя- зано с легированием титана в результате диффузии через сварной шов химических элементов, составляющих сталь 12Х18H10T, так как входящие в ее состав $\mathrm{Fe}, \mathrm{Cr}$ и Ni являются стабилизаторами $\beta$-фазы. Проведение химического анализа околошовной зоны показало наличие $\mathrm{Si}(0,14)$, Ti $(74,41), \mathrm{Cr}(1,85), \mathrm{Mn}(0,11) \mathrm{Fe}(5,92)$, Ni $(0,78)$, $\mathrm{Cu}(16,79)$ в вес.\%. Расчет молибденового эквивалента дал значение $\mathrm{Mo}_{\text {экв}}$, равное 19 , что говорит о том, что титановый сплав в рассматриваемой зоне является псевдо$\beta$-сплавом, поэтому при больших скоростях охлаждения

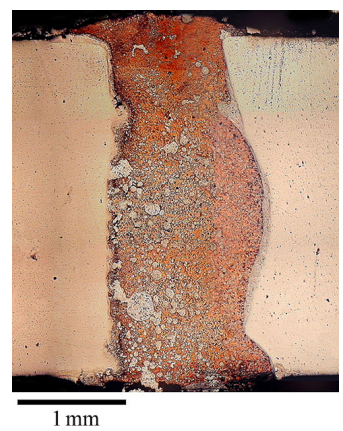

a

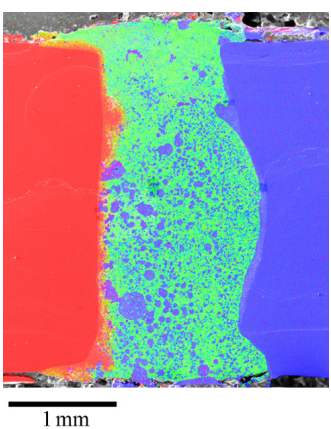

$\mathrm{b}$
Puc. 1. (Color online) Структура сварного шва титан BT1-0 и $12 \mathrm{X} 18 \mathrm{H} 10 \mathrm{~T}$ с промежуточной медной вставкой (a) и распределение химических элементов $\mathrm{Ti}$ (красный), $\mathrm{Fe}$ (синий), $\mathrm{Cu}$ (зеленый) по поперечному сечению шва (b).

Fig. 1. (Color online) Structure of the laser-welded joint of an austenitic corrosion-resistant steel and a titanium alloy with an intermediate copper insert (a) and the distribution of chemical elements $\mathrm{Ti}$ (red), $\mathrm{Fe}$ (blue), $\mathrm{Cu}$ (green) in the cross-section of the weld (b).

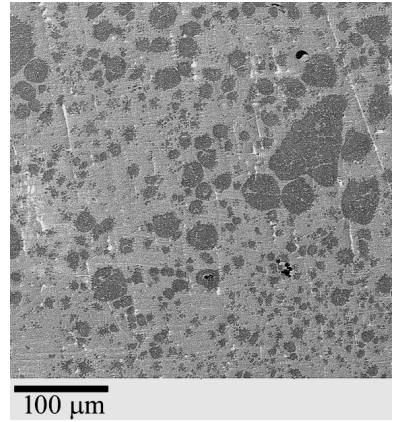

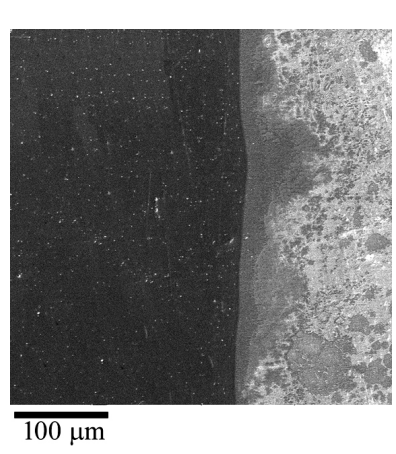

b

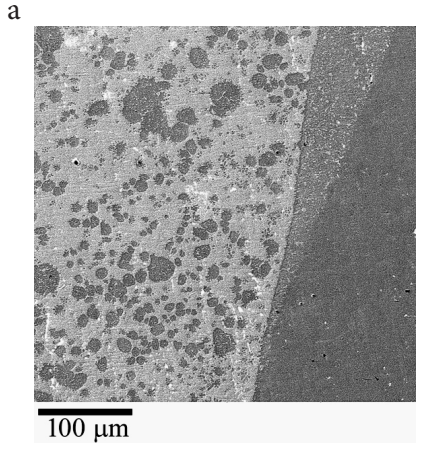

Рис. 2. Структура сварного шва: центральная часть сварного шва (a); переходная зона на границе со сплавом ВТ1-0 (b); переходная зона на границе со сталью 12X18H10T (c).

Fig. 2. Structure of the laser-welded joint: the central part (a); the diffusion zone on the boundary with titanium alloy VT1-0 (b); the diffusion zone on the boundary with 12Cr18Ni10Ti steel (c). 
из $\beta$-области, присущим процессу сварки лазерным лучом, происходит фиксация $\beta$-фазы, что и было обнаружено в результате EBSD-анализа.

Измерения микротвердости и приведенного модуля упругости различных составляющих шва проведены при температуре $22 \pm 0,5^{\circ} \mathrm{C}$ и относительной влажности $45 \pm 2 \%$. Прикладываемая нагрузка во всех случаях была $5 \mathrm{mH}$, время нагружения и разгрузки имели значение 20 с. На Рис. За приведены кривые нагружения для составляющих лазерного шва. На Рис. 3b показана фотография структуры в центральной части с отпечатками индентора в твердом растворе на основе меди и интерметаллиде. Видно, что при внедрении индентора в медь, обладающую более высокой пластичностью по сравнению с частицей интерметаллида, при одинаковых нагрузках размер отпечатка, как и глубина внедрения, оказываются почти в два раза больше. Соответственно, микротвердость стали 12Х18Н10Т находится в диапазоне $2,7 \div 3,1$ ГПа, микротвердость титана ВТ1-0 - 2,4 $\div 2,8$ ГПа. Разброс микротвердости по твердому раствору на основе меди после проплавления незначительный, составляет $1,7 \div 2,1$ ГПа. Микротвердость интерметаллидов варьируется в диапазоне $3,8 \div 4,9$ ГПа, что на порядок выше, чем микротвердость твердого растворе на основе меди, и в два раза выше, чем микротвердость стали 12Х18Н10Т. Со стороны титанового сплава в диффузионной зоне на границе со швом среднее значение микротвердости изменяетсяот 4,6 до 6 ГПа. Разброс значений в диффузионной зоне на границе со сталью $12 \mathrm{X} 18 \mathrm{H} 10 \mathrm{~T}$ находится в диапазоне от 2,9 до 3,4 ГПа. Дополнительный рост микротвердости в диффузионных слоях на границах между швом и соединяемыми материалами связан с образованием пересыщенных твердых растворов.

Экспериментальные средние значения контактного модуля упругости зон сварного соединения имеют следующие значения: интерметаллиды - 220 ГПа, сталь 12Х18Н10T - 200 ГПа, сплав ВТ1-0 - 140 ГПа, твердый раствор на основе меди - 110 ГПа, пограничный слой между зоной шва и сталью $12 \mathrm{X} 18 \mathrm{H} 10 \mathrm{~T}$ - 160 ГПа, пограничный слой между зоной шва и сплавом ВТ1-0 150 ГПа.

Таким образом, на основании изучении микроструктуры и микротвердости, выделены следующие основные составляющие сварного шва: пересыщенный твердый раствор на основе меди; интерметаллиды $\mathrm{TiFe} ; \mathrm{Ti}(\mathrm{Fe}, \mathrm{Cr})_{2}$ и $\mathrm{TiCu}_{3}$; диффузионные зоны на границах со сталью 12X18H10T (пересыщенный твердый раствор на основе Fe) и титаном BT1-0 (пересыщенный твердый раствор на основе $\beta$-Ті и частицы интерметаллида $\mathrm{CuTi}{ }_{2}$ ). Для этих отдельных составляющих с применением методики, описанной в работах $[12,13]$ были определены прочностные свойства. Зная экспериментально полученные значения глубин вдавливания $h_{\text {ind }}$ и царапания $h_{s c r}$ при нагрузке $5 \mathrm{mH}$ для разных участков сварного соединения и, используя результаты многократного моделирования, определили искомую пару значений коэффициентов $a$ и $b$ для всех зон сварного соединения (Табл. 1). На Рис. 4 приведены диаграммы деформационного упрочнения составляющих сварного соединения «сплав
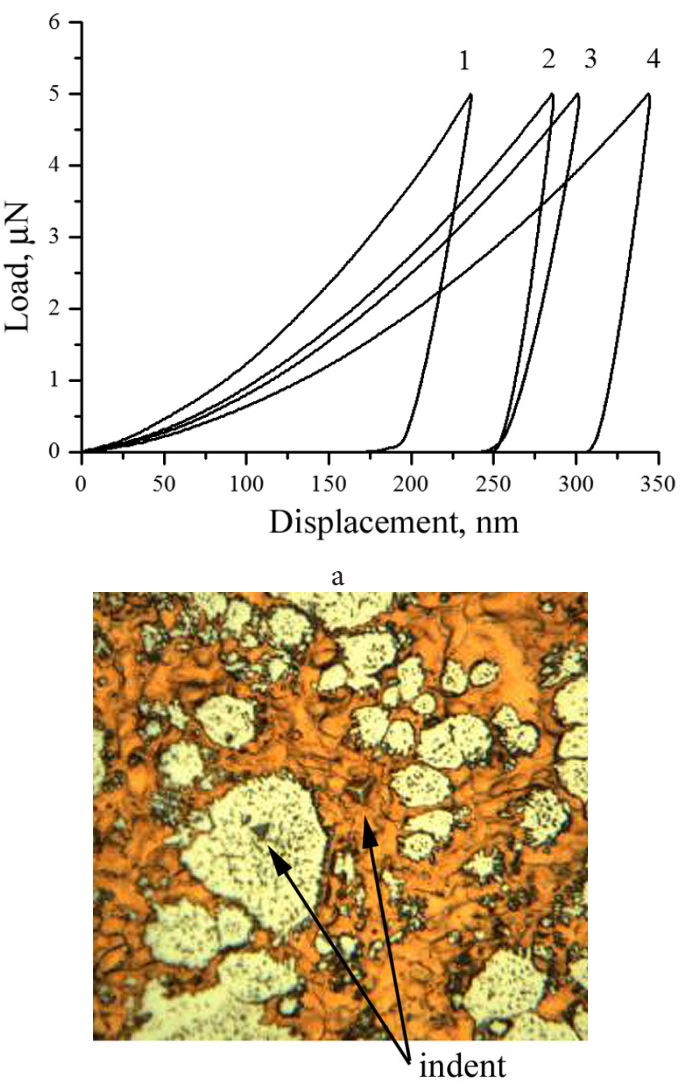

b

Рис. 3. Кривые нагружения при индентировании для составляющих лазерного шва (1 - интерметаллид, 2 - сталь 12Х18Н10Т, 3 - титановый сплав ВТ1-0, 4 - пересыщенный твердый раствор на основе меди) (а) и внешний вид отпечатков в меди и интерметаллиде (b).

Fig. 3. Loading curves for the zones of the laser-welded joint $(1-$ intermetallide, $2-12 \mathrm{Cr} 18 \mathrm{Ni10Ti}$ steel, $3-$ titanium alloy VT1-0, 4 - supersaturated solid solution of copper) (a) and view of indents in copper and intermetallide (b).

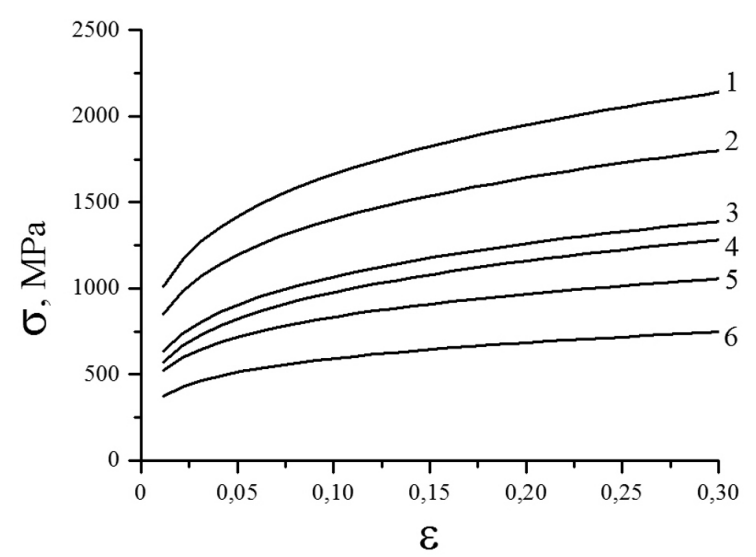

Рис. 4. Диаграммы деформационного упрочнения отдельных составляющих сварного соединения: 1 - диффузионная зона на границе с титановым сплавом, 2 - интерметаллиды, 3 - диффузионная зона на границе со сталью, 4 - сталь 12Х18Н10Т, 5 - титановый сплав ВТ1-0, 6 - пересыщенный твердый раствор на основе меди.

Fig. 4. Stress-strain diagrams of individual zones of laser-welded joint: 1 - diffusion zone on the boundary with titanium, 2 - intermetallides, 3 - diffusion zone on the boundary with steel, $4-12 \mathrm{Cr} 18 \mathrm{Ni10Ti}$ steel, $5-$ titanium alloy VT1-0, 6 - supersaturated solid solution of copper. 
Табл. 1. Результаты измерений свойств сварного соединения.

Table 1. The properties of the laser-welded joint.

\begin{tabular}{|c|c|c|c|c|}
\hline $\begin{array}{l}\text { исследуемый участок } \\
\text { study area }\end{array}$ & $h_{\text {ind }}, \mathrm{nm}$ & $h_{s c r}, \mathrm{~nm}$ & $a, \mathrm{MPa}$ & $b$ \\
\hline $\begin{array}{l}\text { сплав ВТ1-0 } \\
\text { titanium alloy VT1-0 }\end{array}$ & 298 & 238 & 1367 & 0,215 \\
\hline $\begin{array}{l}\text { пограничный слой ВT1-0 - медь } \\
\text { diffusion zoneVT1-0 - copper }\end{array}$ & 217 & 163 & 2818 & 0,229 \\
\hline $\begin{array}{c}\text { пересыщенный твердый раствор на основе меди } \\
\text { solid solution of copper }\end{array}$ & 349 & 286 & 959 & 0,209 \\
\hline $\begin{array}{l}\text { интерметаллиды } \\
\text { intermetallide }\end{array}$ & 236 & 179 & 2374 & 0,229 \\
\hline $\begin{array}{c}\text { пограничный слой медь - сталь 12X18H10T diffusion zone } \\
\text { copper }-12 \text { Cr18Ni10Ti steel }\end{array}$ & 273 & 207 & 1851 & 0,239 \\
\hline $\begin{array}{l}\text { сталь } 12 \mathrm{X} 18 \mathrm{H} 10 \mathrm{~T} \\
12 \mathrm{Cr} 18 \mathrm{Ni} 10 \mathrm{Ti} \text { steel }\end{array}$ & 285 & 217 & 1725 & 0,247 \\
\hline
\end{tabular}

ВТ1-0 - медная вставка - сталь 12Х18Н10Т». Большей прочностью характеризуется пограничный слой «титан ВТ1-0 - медь», затем идут интерметаллиды. Значения прочностных характеристик пограничного слоя «медь сталь 12Х18Н10Т» находятся на уровне самой прочной составляющей стали 12X18H10T. Зная закономерность, что с повышением прочности пластичность уменьшается, можно предсказать, что при нагружении, разрушение в сварном шве произойдет по пограничному слою «титан ВТ1-0 - медь», что подтверждается результатами работы [16].

\section{4. Заключение}

При формировании сварного соединения «сплав ВТ1-0медь - сталь 12Х18H10Т», полученного лазерной сваркой, наблюдается значительное растворение и перемешивание основных свариваемых материалов в медной прослойке. Выявлено четыре структурных составляющих сварного шва, отличающихся по механическим свойствам. Это, во-первых, пересыщенный твердый раствор $\mathrm{Ti}, \mathrm{Fe}, \mathrm{Cr}$, Ni в решетке $\mathrm{Cu}$, во-вторых, интерметаллиды $\mathrm{TiFe}, \mathrm{Ti}(\mathrm{Fe}, \mathrm{Cr})_{2}$ и $\mathrm{CuTi}_{2}$, в-третьих, диффузионная зона между швом и титановым сплавом - пересыщенный твердый раствор $\mathrm{Cu}, \mathrm{Fe}, \mathrm{Cr}, \mathrm{Ni}$ в решетке $\beta$-Ti и частицы интерметаллида $\mathrm{CuTi}_{2}$, в-четвертых, зона между швом и сталью $12 \mathrm{X} 18 \mathrm{H} 10 \mathrm{~T}$ - пересыщенный твердый раствор $\mathrm{Cu}, \mathrm{Ti}, \mathrm{Cr}, \mathrm{Ni}$ в решетке $\alpha$-Fe. Для всех структурных составляющих построены диаграммы деформационного упрочнения. Полученные экспериментальные данные могут быть использованы при решении задач, связанных с оценкой напряженно-деформированного состояния, прочности и работоспособности сварного шва под нагрузкой, позволяют дать практические рекомендации для дальнейшей работы с данным видом сварного шва.
Благодарности/Acknowledgements. Методика исследований разработана в рамках государственного задания ИМАШ УрО РАН (тема 0391-2016-0002, исследования проведень при финансовой поддержке РФФИ, проект №16-38-00741 мол_a./The investigation procedure was developed under the Government Task of IES UB RAS (theme No. 0391-2016-0002); the studies were financially supported by RFBR (project No 16-38-00741 Mol_a).

Дополнительныйматериал/SupplementaryMaterial. Электронная версия статьи содержит дополнительныи материал (рисунки), доступный безвозмездно на сайте журнала (www.lettersonmaterials.com)./The online version of thispaperat the journal's Website (www.lettersonmaterials.com) contains supplementary materials (figures).

\section{Литература/References}

1. Yan Zhang, Da Qian Sun, Xiao Yan Gu, Hong Mei Li. Materials Letters. 185, 152 - 155 (2016).

2. I. Tomashchukn, P. Sallamand, N. Belyavina, M. Pilloz. Materials Science and Engineering: A. 585, 114-122 (2013).

3. A.N. Cherepanov, Yu.V. Afonin, A.M. Orishich. Tyazheloe Mashinostroenie. № 8, 24-26. (2009). (in Russian) [А.Н. Черепанов, Ю.В. Афонин, А. М. Оришич. Тяжелое машиностроение. № 8, 24-26 (2009).].

4. A.M. Orishich, A.N. Cherepanov, V.P. Shapeev, N. B. Pugacheva. Nanomodificirovanie pri lazernoj svarke splavov. Textbook. Novosibirsk: Sibirskoe nauchnoe izdanie. (2014) 258 p. (in Russian) [А.М. Оришич, А.Н. Черепанов, В.П. Шапеев, Н.Б. Пугачева. Наномодифицирование при лазерной сварке сплавов. Новосибирск: Сибирское научное издание. 2014. 258 c.] 
5. N.B. Pugacheva, S.V. Smirnov, D.I. Vichuzhanin, S.M. Zadvorkin, L.S. Goruleva. Deformacijairazru sheniematerialov. № 7, 26-33 (2012). (inRussian) [Н.Б. Пугачева, С.В. Смирнов, Д.И. Вичужанин, С.М. Задворкин, Л.С. Горулева. Деформация и разрушение материалов. № 7, 26 - 33 (2012).]

6. N.B. Pugacheva, E.B. Trushina, E.I. Pugacheva, A.M. Orishich, A.N. Cherepanov. Voprosymaterialovedenija. № 1, $166-174 \quad$ (2013). (inRussian) [Н.Б. Пугачева, Е.Б. Трушина, Е.И. Пугачева, А.М. Оришич, А.Н. Черепанов. Вопросыматериаловедения. № 1, 166 - 174 (2013).]

7. A.N. Cherepanov, A.M. Orishich, N.B. Pugacheva, V.P. Shapeev. Teplofizikaiajeromehanika. T. 22, № 2, 143 - 150 (2015). (inRussian) [A.H. Черепанов, А. М. Оришич, Н. Б. Пугачева, В. П. ШапеевТеплофиз икаиаэромеханика. Т. 22, № 2, 143 - 150 (2015).]

8. S. V. Kuryntsev, A.E. Morushkin, A. Kh. Gilmutdinov. Optics and Lasers in Engineering. 90, 101 - 109 (2017).

9. I. Tomashchuka, P. Sallamanda, E. Cicalaa, P. Peyreb, D. Greveya. Journal of Materials Processing Technology. 217, 96 - 104 (2015).

10. I. Magnabosco, P. Ferro, F. Bonollo, L. Arnberg. Materials Science and Engineering: A. 424, 163 - 173 (2006).
11. Mutiu F. Erinosho, Esther T. Akinlabi, Sisa Pityana.Trans. Nonferrous Met. Soc. China. 25, 2608-2616 (2015).

12. S. V. Smirnov, E. O. Smirnova. Journal of Materials Research. V. 29, № 16. 1730 - 1736. (2014)

13. S.V. Smirnov, E.O. Smirnova, I.A. Golubkova. Vestnik permskogo nacional"nogo issledovatel"skogo politehnicheskogo universiteta. Mehanika. № 2, 84-91 (2011). (in Russian) [С. В. Смирнов, Е. О. Смирнова, И.А. Голубкова. Вестник пермского национального исследовательского политехнического университета. Механика. № 2, 84 - 91 (2011).]

14. A. A. Il'in, B. A. Kolachev, I. S. Pol'kin. Titanovye splavy. Sostav, struktura, svojstva. Textbook. Spravochnik. Moskva, VILS-MATI. (2009) 520 p. (in Russian) [А. А. Ильин, Б. А. Колачев, И. С. Полькин.Титановые сплавы. Состав, структура, свойства. Справочник. Москва, ВИЛС-МАТИ. 2009.520 с.]

15. W.C. Oliver, G. M. J. Mater. Res. 1992. V. 7. № 6. $1554-1583$ (1992).

16. N.B. Pugacheva, M.V. Mjasnikova, N.S. Michurov. Fizika metallov i metallovedenie. T. 117, № 2, 204-212 (2016). (in Russian) [Н.Б. Пугачева, М.В. Мясникова, Н. С. Мичуров. Физика металлов и металловедение. T. 117, № 2, $204-212$ (2016).] 